\author{
В.Ж. Дубровский, Е.В. Рожков
}

\author{
ПРОБЛЕМЫ ФОРМИРОВАНИЯ ЦИФРОВОЙ ПЛАТФОРМЫ \\ УПРАВЛЕНИЯ МУНИЦИПАЛЬНОЙ СОБСТВЕННОСТЬЮ
} (НА ПРИМЕРЕ ГОРОДА ПЕРМИ)

Проведено исследование проблем, связанных с формированием и внедрением цифровой платформы управления собственностью на примере муниципального образования.

Методологическая база исследования включает теоретические положения метода системного анализа, теории цифровизации систем, расчетно-экспериментальных методик моделирования цифровизации платформ для собственности муниципального образования, а также методов, базирующихся на теории функциональной специализации и теории реструктуризации. В исследовании использовался метод наблюдений, в рамках которого было определено, какие цели необходимо достичь, какие процессы необходимо осуществить при цифровизации платформ городской собственности. Проведен анализ собранной информации, целью которого было определить необходимость применения программно-целевого подхода для цифровизации собственности.

Полученные результаты показали, что отсутствие цифровых инновационных платформ в управлении муниципальной собственности имеет серьезные последствия для развития городского хозяйства, что может привести в дальнейшем к более глубокому отставанию от крупных, развитых цифровых городов в инновационном развитии. Пермский технопарк «Morion Digital», входящий в группу «A+» всех технопарков нашей страны, на сегодняшний день уже готов заниматься разработкой любых цифровых платформ как для города Перми, так и для других муниципальных образований региона.

Теоретическая и практическая значимость исследования говорит о том, что цифровая платформа позволит пользователям в 100 \% муниципальных услуг по управлению собственностью предоставляться по модели реестра в проактивном онлайн-режиме без очного посещения городских подразделений администрации. Для жителей города Перми цифровые платформы обеспечивают доступ к большому выбору услуг при минимуме затрат и предоставляют удобные функции, а также индивидуальные услуги.

Ключевые слова: городская собственность, платформа, цифровизация, умный город, экономическая выгода.

Введение. Цифровые технологии, цифровые трансформации и цифровые платформы активно внедряются во всем мире. Например, в Германии разработана концепция «Индустрия 4.0», а в целом в странах Евросоюза сформирован план действий по цифровизации экономики [1-6]. Цифровая платформа муниципальной собственности в России формируется с разным уровнем успеха изза тех или иных имеющихся проблем по внедрению автоматизированных сис-

(С) Дубровский В.Ж., Рожков Е.В., 2021

Дубровский Валерий Жоресович - д-р экон. наук, профессор, директор Института экономики, ФГБОУ ВО «Уральский государственный экономический университет», e-mail: dubr@usue.ru.

Рожков Евгений Викторович - соискатель кафедры экономики предприятий, ФГБОУ ВО «Уральский государственный экономический университет», e-mail: rozhkov@pochtobank.ru. 
тем управления [7]. На региональных уровнях внедряемые информационные технологии дают возможность администрациям взаимодействовать с городскими инфраструктурами напрямую, осуществлять контроль за происходящим [8]. В Пермском крае реализуется утвержденная Концепция развития цифровой экономики, которая создает условия для муниципалитетов по развитию экономики и общества [9]. В городе Перми реализуются муниципальные программы по технологиям «умного города» [10].

Цель исследования - выявить новые возможности формирования цифровой платформы по управлению городской собственностью. Задача исследования - определить основные направления по решению имеющихся проблем при внедрении цифровой платформы управления собственностью.

Теоретико-методологическая актуальность данной работы заключается:

- в недостаточной развитости нормативно-правовых актов по созданию и внедрению цифровой платформы управления собственностью на уровне муниципалитетов;

• в выявлении экономической необходимости внедрения цифровой платформы по управлению муниципальной собственностью;

- в необходимости изменения федерального законодательства, регламентирующего работу по управлению муниципальной собственностью.

Актуальность вопроса о необходимости наличия цифровой платформы муниципальной собственности бесспорна. Экономический эффект от ее внедрения по сравнению со стоимостью установки видится только в ежегодной экономии бюджетных средств.

Практическая значимость исследования заключается в выявлении имеющихся проблем по внедрению цифровой платформы управления собственностью на уровне муниципального образования и определения путей их решения.

Цифровые платформы в разные годы изучали как зарубежные ученые (M. Billon [11], J. Bryson [12], K. Warwick [13]), так и российские (В.В. Григорьева [14], Л.И. Прокопова [15] и др.).

А.М. Ёлохов, анализируя место нахождения России в мировом рейтинге по цифровому рынку, определил 40-ю позицию, что характеризует невысокую оценку степени инновационности [10]. Особую значимость для местного самоуправления повышения эффективности управления муниципальной собственностью приобретают вопросы цифровизации процессов управления [16].

Н.В. Казанцева и И.В. Милькина определили роль цифровых платформ в условиях цифровизации муниципального управления собственностью как системы управления интеллектуальной системы общественной безопасности, инфраструктуры сетей связи, умного жилищно-коммунального хозяйства, систем умного городского транспорта, инноваций городской среды [17].

Цифровые платформы создают оборудование и программное обеспечение, необходимое для перевода традиционного производства на интернет-рельсы для 
снижения производственных издержек, и строиться они должны на основных ценностях «умного города» [18]. А.В. Алтухов и С.Ю. Кашкин считают, что как разработчикам, так и пользователям цифровых платформ, приходится переосмыслять существующие нормативно-правовые акты и учитывать зарубежные разработки на основе ИКТ, IoT, Big Data и технологии блокчейн [18].

М.Ю. Казаков считает, что существует объективная необходимость формирования на уровне города интегрированной информационно-аналитической системы, с помощью которой имелась бы возможность проводить тактические обоснования по проблемным аспектам социально-экономической динами муниципального образования [19]. По мнению Е.А. Фроловой и Е.Г. Щербань, станет возможно решать задачи по объединению учета муниципальной собственности в единую информационную систему [20].

Цифровизация управления муниципальной собственностью способствует повышению уровня использования электронных услуг, предоставляемых муниципальным образованием города Перми при имеющихся расхождениях административных регламентов разных ведомств и нормативных правовых актов [21]. Информационно-аналитические системы - это системы сбора, обработки, хранения и передачи статистической, экспертно-аналитической и юридически значимой информации о хозяйственных действиях лиц, выступающих в качестве контрагентов институтов публичного права [22].

Tеория. Город Пермь участвует в пилотном проекте «Умный город», который в нашей стране реализуется под контролем Министерства строительства и жилищно-коммунального хозяйства Российской Федерации и Министерства цифрового развития Российской Федерации [23] и в соответствии с определенным федеральным финансированием. И по многочисленным требованиям и критериям «Умного города» собственность муниципального образования должна перейти в «цифру».

К муниципальному имуществу относятся жилые и нежилые фонды, имущество предприятий торговли и общественного питания, бытового обслуживания, строительного комплекса, транспорта, учреждений культуры, образования и т.д. [17]. И эффективность использования муниципальной собственности становится важнейшей задачей местных органов власти [17], которая не осуществима без внедрения цифровых платформ.

Муниципальная цифровая платформа предназначена для создания единой информационно-управляющей городской системы с целью повышения общего уровня эффективности управления муниципальной собственностью. Реализация муниципальной цифровой платформы осуществляется в соответствии с Указом Президента Российской Федерации от 07.05.2018 № 204 «О национальных целях и стратегических задачах развития Российской Федерации на период до 2024 года» [10], Федеральным законом Российской Федерации от 31.07.2020 № 258-Ф3 «Об экспериментальных правовых режимах в сфере 
цифровых инноваций в Российской Федерации». Цифровые инновации - это новые (существенно улучшенные) процессы, организационные методы управления, в том числе в управлении муниципальной собственностью.

Цифровая платформа - это инструмент трансформации системы управления собственностью в пользу более справедливой и прозрачной конкуренции на основе цифрового муниципального регулирования.

Информационные данные о собственности, выделенные в научной литературе и нормативно-регламентирующих документах, не эквивалентны по составу, качеству и количеству [24]. Типы и владельцы городских данных [24]: владельцем открытых данных является частный и государственный сектор; данные, собранные с помощью сенсоров или других устройств, находятся в государственной собственности.

Если есть необходимость снизить трудозатраты, эти данные обрабатываются автоматически, с использованием информационных и коммуникационных технологий.

Информационные и коммуникационные технологии (ИКТ) - это технологии, использующие средства микроэлектроники для сбора, хранения обработки, поиска, передачи и предоставления данных, текстов и т.д.

При использовании цифровизации муниципальной собственности могут быть сформированы новые коммуникационные каналы между жителями города и административными органами управления муниципальным имуществом, что в свою очередь способствует решению задачи по повышению уровня отзывчивости органов самоуправления к потребителям услуг посредством активного присутствия в разработанных приложениях на сайте муниципального образования на основе цифровой платформы [20]. Созданная (установленная) цифровая платформа для регулирования процессов, связанных с муниципальной собственностью, позволит сформировать онлайн актуальную интегрированную базу сведений обо всех имущественных объектах, а также обращенного в собственность муниципалитета и иного изъятого имущества, которая основана на первичных данных иных цифровых платформ.

Для обеспечения полноты и достоверности данных о муниципальном имуществе должны реализоваться следующие мероприятия:

1) реализация интеграционного взаимодействия единой информационной системы управления муниципальным имуществом с информационными системами муниципальных органов власти посредством единого интеграционного решения для получения сведений об имуществе;

2) ведение интерактивной электронной базы данных об имуществе, предлагаемом к реализации, его характеристиках и текущем состоянии, проводимых по нему торгах, что предоставляет возможность выгрузки полной информации в заинтересованные органы, обработки и поиска информации в электронном виде по заданным параметрам, учитывающим особенности выставленного на продажу 
имущества, а также наделение данного ресурса информационно-логистическими функциями между электронными площадками и т.д.

Maтериалы и методы. Цифровизация управления муниципальной собственности является электронным элементом выражения методологических положений системной экономики [25]. Общий механизм создания системноцифровой экономики представлен на рисунке.

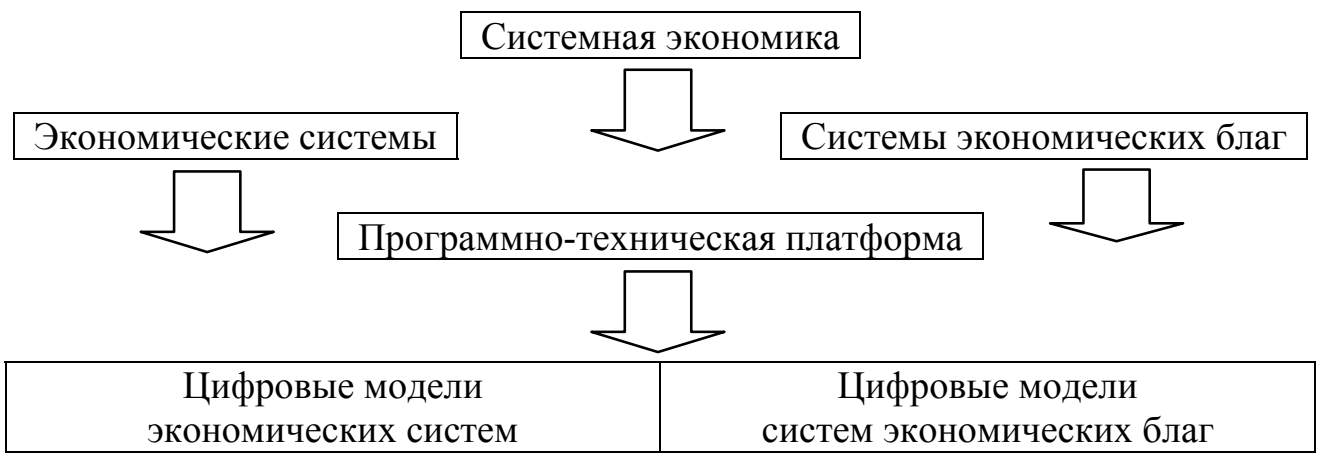

Рис. Механизм создания системно-цифровой экономики [25]

Как видно на рисунке, системная экономика является неким «заказчиком» по отношению к цифровой экономике и определяет содержание и направленность ее дальнейшего развития [25].

В ходе работы над статьей был применен общенаучный метод познания проблемы и метод системного анализа [26], теории цифровизации систем, расчетноэкспериментальные методики моделирования цифровизации платформ для собственности муниципального образования, а также методы, базирующиеся на теории функциональной специализации и теории реструктуризации [27].

В исследовании использовался метод наблюдений, в рамках которого было определено, какие цели необходимо достичь при цифровизации платформ городской собственности. Проведен анализ собранной информации, согласно которому была определена необходимость применения программно-целевого подхода для применения цифровизации собственности. При программно-целевом подходе выявляется проблема и соответственно задачи ее решения. На основании поставленных задач разрабатывается примерная программа и мероприятия по ее реализации, подтверждающиеся соответствующими бюджетными расходами. Завершающим этапом будет контроль реализованных мероприятий на разных этапах (планирование, выделение бюджетных средств, реализация первой части, второй части и завершающей части запланированных мероприятий).

Рассмотрим несколько цифровых платформ по управлению муниципальной собственностью. 
1. Платформа «eOctopus» - автоматизация технологических процессов, решение задач класса АСУ ТП, мониторинг объектов инженерной инфраструктуры. Решения на базе платформы «еOctopus» обеспечивают:

- мониторинг, диспетчерское управление, контроль качества и эффективности работы систем электроснабжения, водоснабжения, водоотведения и других инженерных систем;

- централизованный сбор информации с приборов учета потребления ресурсов;

- мониторинг и контроль работы муниципального, коммунального и общественного транспорта;

• мониторинг экологической и метеорологической обстановки;

- развертывание муниципальных ситуационных центров;

- предоставление информации в ЕДДС, «112» и другие службы.

2. Платформа «Carrot»- автоматизация процессов управленческих решений и управления ресурсами. Решения на базе данной платформы обеспечивают реализацию следующих функциональных возможностей:

• контроль исполнения показателей эффективности;

- ведение электронного документооборота;

• контроль исполнения бюджета;

- контроль исполнения муниципальных программ;

- ведение реестров: муниципальных дорог, имущества, коммунальных и инженерных систем, договорной и отчетной документации, ветхого и аварийного жилья, земельных участков, объектов критической инфраструктуры и т.д.

3. Платформа «EtherSensor» - анализ сетевого трафика для задач класса: DLP, SIEM, DPI. Особенностью платформы является возможность автоматизации на одной платформе практически всех сфер управления муниципального имущества: от получения инструментальных данных до аналитики принятия управленческих решений. Внедрение решений на базе единой платформы позволяет значительно снизить бюджетные затраты на разработку и эксплуатацию отдельных решений, включая затраты на интеграцию. Данная платформа обладает высокой адаптируемостью при внедрении на уже существующей информационно-технологической инфраструктуре муниципалитета.

Поддержка протоколов обмена данными позволяет интегрироваться практически с любыми технологическими или информационными системами, а именно:

- системами видеонаблюдения;

- системами локальной автоматики;

- датчиками, измерителями, исполнительными механизмами;

- системами контроля и управления доступом;

• информационными программными комплексами; 
- учетными системами;

- системами электронного документооборота.

Встроенные инструменты платформы - ядро, модули сбора и обработки, модули работы с базами данных, инструменты произвольного конфигурирования рабочих мест, инструменты обработки и предоставления данных, модули интеграции, конструкторы отчетов и другие компоненты - позволяют создавать на базе одной платформы большое количество решений. Работа с системой осуществляется посредством «тонкого клиента» и не требует установки локального программного обеспечения на рабочем месте пользователей.

Результаты и обсуждение. Отсутствие цифровых инновационных платформ в управлении муниципальной собственности имеет серьезные последствия для развития городского хозяйства, что может повлечь за собой в дальнейшем более глубокое отставание от крупных, развитых цифровых городов в инновационном развитии.

Рынок цифровых платформ управления собственности в нашей стране активно развивается. С 2020 г. Пермский технопарк «Morion Digital» в соответствии с рейтингом Ассоциации кластеров и технопарков России вошел в группу «A+», что говорит о его высоких технических показателях и возможности разработки любых платформ для муниципального образования. Использование цифровой платформы («eOctopus», «Carrot» или «EtherSensor») при управлении муниципальной собственности позволит:

- получать полную и достоверную картину состояния собственности муниципального образования город Пермь;

- получать полную информацию и достоверные данные о работе городских систем жизнеобеспечения;

- повышать качество, скорость и прозрачность принятия управленческих решений;

- повышать эффективность и качество управления муниципальным имуществом;

- снизить риски возникновения техногенных аварий;

- повысить скорость реагирования на аварийные и нештатные ситуации;

- эффективно использовать энергоресурсы;

- обеспечить население города Перми электронными сервисами для получения услуг, работы с данными местных органов власти.

Внедрение цифровых платформ на уровне муниципалитета невозможно без модификации гражданского и отраслевого законодательного регулирования, направленного на стимулирование конкуренции между различными платформами в отрасли. Необходимо усилить антимонопольное законодательство, с учетом ограниченной конкуренции. Соответственно, как и при внедрении чего-либо нового, имеются ряд трудностей, которые необходимо будет преодолевать: естественное сопротивление ряда традиционных структур 
управления; недостаток опыта в построении подобного рода платформ; определенная «инертность» [28] городских жителей при использовании таких цифровых платформ и т.д.

Bbывоы. За несколько лет город Пермь должен продвинуться в цифровизации основных сфер экономики, должна быть построена инфраструктура, проложены сети и вся городская территория должна быть покрыта 5G. Применение цифровой платформы при управлении муниципальной собственностью основано на существующей базе данных. Это в дальнейшем позволит снизить расходы бюджета города Перми на приобретение разрозненных информационных и технологических программно-аппаратных комплексов; достичь оптимизации человеческих и технических ресурсов, используемых городской администрацией и повысить инвестиционную привлекательность муниципального образования. Также цифровая платформа позволит 100 \% муниципальных услуг по управлению собственностью предоставлять по модели реестра в проактивном онлайн-режиме без очного посещения городских подразделений администрации.

Кроме того, внедрение цифровой платформы управления ведет к трансформации рынка труда на уровне муниципалитета и появлению новых форм занятости среди муниципальных служащих. Следовательно, все большее количество работников муниципальных учреждений будут пользоваться платформой муниципального образования для исполнения своей работы по управлению городской собственностью. Для жителей города Перми цифровые платформы обеспечивают доступ к большому выбору услуг при маленьких затратах и предоставляют удобные функции, а также индивидуальные услуги. Потребители могут получить дополнительную выгоду, получая услуги быстрее благодаря отсутствию какого-либо препятствий.

Таким образом, дальнейшая проработка вопросов, связанных с внедрением цифровой платформы управления муниципальной собственностью, представляется перспективным направлением для исследования и практического применения не только на уровне города Перми, но и на региональном уровне, а изложенные результаты могут войти в соответствующие программы муниципального и регионального развития.

\section{Список литературы}

1. Афанасьев O.A. Использования Digital-технологий коммуникаций в маркетинге в условиях перехода к цифровой экономике // Аллея Науки. - 2017. T. 2, № 16. - С. 62-66.

2. Franklin N.M., Prince N., Daniel D. Farmers' willingness to pay for weather forecast information in savelugu - nanton municipality of the northern region // Russian Journal of Agricultural and Socio-Economic. Sciences. - 2014. - No. 12 (36). P. 34-44. 
3. Lopez-Morales J.A., Martinez J.A., Skarmeta A. F. Digital Transformation of Agriculture through the Use of an Interoperable Platform // Sensors. - 2020. No. 20 (4). - P. 1153.

4. Made F.N., Sarpong D.B., Osei-Asare Y. Empirical Evidence of Climate Change: Effects on Rice Production in the Northern Region of Ghana // British Journal of Economics, Management and Trade. - 2014. - No. 4 (4). - P. 551-562.

5. Machova R., Lnenicka M. Reframing E-Government Development Indices with Respect to New Trends in ICT // Review of Economic Perspectives. Narodohospodarsky Obzor. - 2015. - Vol. 15, no. 4. - P. 383-411.

6. Morakanyane R., O’Reilly Ph., Mc Avoy J. Determining digital transformation success factors // Proceedings of the $53^{\text {rd }}$ Hawaii International conference on system sciences, 2020. - P. 4356-4365.

7. Шипилов М.А., Шипилова С.М. О проекте «умный муниципалитет» // Наука XXI века: проблемы, поиски, решения: материалы XLI науч.-практ. конф. - Миасс, 2017. - С. 171-177.

8. Денисов В.А., Шаронина Л.В. Современные информационные технологии в развитии умных городов России // Vector Economy. - 2019. - № 7 (37). - С. 35.

9. Сердюкова О.А. Цифровая экономика Пермского края: состояние и перспективы развития // Экономика и бизнес: теория и практика. - 2019. № 8. - C. $138-144$.

10. Ёлохов А.М. Совершенствование методики оценки внедрения технологий «умного города» в крупнейших городах России // Экономика и бизнес: теория и практика. - 2020. - № 5-1 (63). - С. 177-183.

11. Billon M., Lerra-Lopez F., Marco R. Differences in digitalization levels: a multivariate analysis studying the global digital divide. Review of World Economics. - 2010. - Vol. 146, no. 1. - P. 39-73.

12. Bryson J., Crosby B., Bloomberg I. Public value governance: Moving beyond traditional // Public administration and the new public management. Public Administration Review. - 2014. - Vol. 74, no. 4. - P. 445-456.

13. Warwick K. Beyond Industrial Policy: Emerging Issues and New Trends. OECD Publishing, 2013. - No. 2. - 56 p.

14. Григорьева В.В. Управление ТЭК и ЖКХ городской агломерации как метасистемой на базе ключевых технологий цифровой экономики // STUDENT RESEARCH: сб. ст. III Междунар. науч.-практ. конкурса. - Пенза, 2018. - C. 121-124.

15. Прокопова Л.И. Разработка комплексных мероприятий по повышению эффективности системы управления муниципальным образованием на основе цифровой трансформации // Известия Юго-Западного государственного университета. Экономика. Социология. Менеджмент. - 2020. - Т. 10, № 4. - С. 226-234.

16. Салабутин А.В., Процай А.Ф. Вопросы цифровизации муниципального управления: тенденции // Наука без границ. - 2020. - № 5 (45). - С. 139-144. 
17. Казанцева Н.В., Милькина И.В. Проблемы формирования муниципальной имущественной политики в условиях цифровизации // Муниципальная Академия. - 2019. - № 2. - С. 89-93.

18. Алтухов А.В., Кашкин С.Ю. Юридические аспекты цифровых платформенных технологий управления «умными городами»// Вестник Российского нового университета. Человек и общество. - 2020. - № 1. - С. 77-82.

19. Казаков М.Ю. Разработка информационно-аналитической платформы для диагностики проблем развития периферийных территорий // Вызовы цифровой экономики: ключевые институты, инфраструктура: сб. ст. I Всерос. науч.-практ. конф. - Брянск, 2018. - С. 210-213.

20. Фролова Е.А., Щербань Е.Г. Цифровая экономика: муниципальный аспект // Вестник СГСЭУ. - 2019. - № 1 (75). - С. 17-21.

21. Сидоренко Э.Л., Барциц И.Н., Хисамова З.И. Эффективность цифрового государственного управления: теоретические и прикладные аспекты // Вопросы государственного и муниципального управления. - 2019. - № 2. - С. 93-114.

22. Гордеев Д.А. Государство 4.0. цифровая трансформация систем государственного управления // Всероссийская весенняя школа по цифровой экономике: сб. науч. тр. / Тюм. гос. ун-т, Финанс.-экон. ин-т. - Тюмень, 2020. - С. 98-103.

23. Цветков Ю.А. Оценка уровня цифровой трансформации городской среды в концепции «умный город» // Вестник Белого генерала. - 2020. - № 2. C. 54-64.

24. Кононова О.В., Павловская М.А. Технологии цифровой экономики в проектах умный город: участники и перспективы // Современные информационные технологии и ІТ-образование. - 2018. - Т. 14, № 3. - С. 692-706.

25. Минапова Р.Я. Целевые ориентиры и актуальные направления реализации национального проекта «Цифровая экономика» в России // Вестник Российского университета кооперации. - 2020. - № 1 (39). - С. 60-63.

26. Темнов Э.С. Применение методик разработки транспортных стратегий (на примере городского пассажирского транспорта) // Вестник СибАДИ. 2018. - Т. 15, № 6 [Сквозной номер выпуска - 64]. - С. 886-897.

27. Разорвин И.В., Рожков Е.В. Институциональные проблемы государственного управления экономикой // Вопросы управления. - 2015. - № 4 (16). С. $138-144$.

28. Ирхин Ю.В. Эффекты использования цифровых технологий в модернизации государственного управления в России // Россия: тенденции и перспективы развития: материалы ХІХ Нац. науч. конф. - М., 2019. - С. 111-115.

\section{References}

1. Afanas'ev O.A. Ispol'zovaniia digital-tekhnologii kommunikatsii v marketinge $\mathrm{v}$ usloviiakh perekhoda $\mathrm{k}$ tsifrovoi ekonomike [The use of digital communication tech- 
nologies in marketing in the context of the transition to the digital economy]. Alleia Nauki, 2017, vol. 2, no. 16, pp. 62-66.

2. Franklin N., Prince N., Daniel D. Farmers' willingness to pay for weather forecast information in Savelugu - Nanton municipality of the northern region. Russian Journal of Agricultural and Socio-Economic Sciences, 2014, no. 12 (36), pp. 34-44.

3. Lopez-Morales J.A., Martinez J.A., Skarmeta A.F. Digital transformation of agriculture through the use of an interoperable platform. Sensors, 2020, no. 20(4), $1153 \mathrm{p}$.

4. Made F., Sarpong D., Osei-Asare Y. Empirical evidence of climate change: Effects on rice production in the northern region of Ghana. British Journal of Economics, Management and Trade, 2014, no. 4(4), pp. 551-562.

5. Machova R., Lnenicka M. Reframing e-government development indices with respect to new trends in ICT. Review of Economic Perspectives. Narodohospodarsky Obzor, 2015, vol. 15, no. 4, pp. 383-411.

6. Morakanyane R., O’Reilly Ph., Mc Avoy J. Determining digital transformation success factors. Proc. of the 53rd Hawaii International conference on system sciences, 2020, pp. 4356-4365.

7. Shipilov M.A., Shipilova S.M. O proekte "umnyi munitsipalitet" [About the "smart municipality" project]. Nauka XXI veka: problemy, poiski, resheniia. Proc. 12th Acad. Conf. (Miass, 28 April, 2017). Miass, 2017, pp. 171-177.

8. Denisov V.A., Sharonina L.V. Sovremennye informatsionnye tekhnologii v razvitii umnykh gorodov Rossii [Modern information technologies in the development of smart cities in Russia]. Vector Economy, 2019, no. 7(37), 35 p.

9. Serdiukova O.A. Tsifrovaia ekonomika Permskogo kraia: sostoianie i perspektivy razvitiia [Digital economy of the Perm Territory: State and development prospects]. Ekonomika i biznes: teoriia i praktika, 2019, no. 8, pp. 138-144.

10. Elokhov A.M. Sovershenstvovanie metodiki otsenki vnedreniia tekhnologii "umnogo goroda" v krupneishikh gorodakh Rossii [Improving the methodology for assessment the implementation of "smart city" technologies in the largest cities of Russia]. Ekonomika i biznes: teoriia i praktika, 2020, no. 5-1 (63), pp. 177-183.

11. Billon M., Lerra-Lopez F., Marco R. Differences in digitalization levels: a multivariate analysis studying the global digital divide. Review of World Economics, 2010, vol. 146, no. 1, pp. 39-73.

12. Bryson J., Crosby B., Bloomberg I. Public value governance: moving beyond traditional. Public Administration and the New Public Management. Public Administration Review, 2014, vol. 74, no. 4, pp. 445-456.

13. Warwick K. Beyond industrial policy: Emerging issues and new trends. OECD Publishing, 2013, no. 2, 56 p. 
14. Grigor'eva V.V. Upravlenie TEK i ZhKKh gorodskoi aglomeratsii kak metasistemoi na baze kliuchevykh tekhnologii tsifrovoi ekonomiki [Management of fuel and energy complex and housing and communal services of urban agglomeration as a metasystem based on key technologies of the digital economy]. Student Research. Proc. III Int. Acad. Contest. Penza, 2018, pp. 121-124.

15. Prokopova L.I. Razrabotka kompleksnykh meropriiatii po povysheniiu effektivnosti sistemy upravleniia munitsipal'nym obrazovaniem na osnove tsifrovoi transformatsii [Development of comprehensive measures to improve the efficiency of the municipal administration system based on digital transformation]. Izvestiia IugoZapadnogo gosudarstvennogo universiteta. Ekonomika. Sotsiologiia. Menedzhment, 2020, vol. 10, no. 4, pp. 226-234.

16. Salabutin A.V., Protsai A.F. Voprosy tsifrovizatsii munitsipal'nogo upravleniia: tendentsii [Issues of digitalization of municipal government: trends and problems]. Nauka bez granits, 2020, no. 5 (45), pp. 139-144.

17. Kazantseva N.V., Mil'kina I.V. Problemy formirovaniia munitsipal'noi imushchestvennoi politiki $\mathrm{v}$ usloviiakh tsifrovizatsii [Problems of formation of a multipolar financial system under the centralisation of global capital]. Munitsipal'naia Akademiia, 2019, no. 2, pp. 89-93.

18. Altukhov A.V., Kashkin S.Iu. Iuridicheskie aspekty tsifrovykh platformennykh tekhnologii upravleniia «umnymi gorodami» [Legal aspects of digital platform technologies for the management of "smart cities"]. Vestnik Rossiiskogo novogo universiteta. Chelovek i obshchestvo, 2020, no. 1, pp. 77-82.

19. Kazakov M.Iu. Razrabotka informatsionno-analiticheskoi platformy dlia diagnostiki problem razvitiia periferiinykh territorii [Development of an information and analytical platform for development problems diagnostics of peripheral territories]. Vyzovy tsifrovoi ekonomiki: kliuchevye instituty, infrastruktura. Proc. 1st AllRuss. Conf. Briansk, 2018, pp. 210-213.

20. Frolova E.A., Shcherban' E.G. Tsifrovaia ekonomika: munitsipal'nyi aspect [Digital economy: municipal aspect]. Vestnik SSTU, 2019, no. 1(75), pp. 17-21.

21. Sidorenko E.L., Bartsits I.N., Khisamova Z.I. Effektivnost' tsifrovogo gosudarstvennogo upravleniia: teoreticheskie i prikladnye aspekty [The effectiveness of digital public administration assessing: Theoretical and applied aspects]. Public Administration Issues, 2019, no. 2, pp. 93-114.

22. Gordeev D.A. Gosudarstvo 4.0. tsifrovaia transformatsiia sistem gosudarstvennogo upravleniia [State 4.0. digital transformation of public administration systems]. Vserossiiskaia vesenniaia shkola po tsifrovoi ekonomike, Tyumen, Tyumen State University, 2020, pp. 98-103.

23. Tsvetkov Iu.A. Otsenka urovnia tsifrovoi transformatsii gorodskoi sredy v kontseptsii "umnyi gorod" [Assessment of the level of digital transformation of 
the urban environment in the concept of "smart city"]. Vestnik Belogo generala, 2020, no. 2, pp. 54-64.

24. Kononova O.V., Pavlovskaia M.A. Tekhnologii tsifrovoi ekonomiki v proektakh umnyi gorod: uchastniki i perspektivy [Digital economy technologies in smart city projects: participants and perspectives]. Modern Information Technologies and IT-Learning, 2018, vol. 14, no. 3, pp. 692-706.

25. Minapova R.Ia. Tselevye orientiry i aktual'nye napravleniia realizatsii natsional'nogo proekta "tsifrovaia ekonomika" v Rossii [Target guidelines and actual directions of implementation of the national project "digital economy" in Russia]. Vestnik Rossiiskogo universiteta kooperatsii, 2020, no. 1(39), pp. 60-63.

26. Temnov E.S. Primenenie metodik razrabotki transportnykh strategii (na primere gorodskogo passazhirskogo transporta) [Methologie's application for the development of transport strategy (urban passenger transport)]. Vestnik SibADI, 2018 , vol. 15 , no. 6 , iss. 64 , pp. $886-897$.

27. Razorvin I.V., Rozhkov E.V. Institutsional'nye problemy gosudarstvennogo upravleniia ekonomikoi [Institutional problems of the economy public administration]. Voprosy upravleniia, 2015, no. 4(16), pp. 138-144.

28. Irkhin Iu.V. Effekty ispol'zovaniia tsifrovykh tekhnologii v modernizatsii gosudarstvennogo upravleniia $\mathrm{v}$ Rossii [Effects of using digital technologies in public administration modernisation in Russia]. Rossiia: tendentsii $i$ perspektivy razvitiia. Proc. 19th Nat. Acad. Conf. Moscow, 2019, pp. 111-115.

Оригинальность $77 \%$

Получено 08.12.2020 $\quad$ Принято 28.12.2020 Опубликовано 31.03.2021

\author{
V.Zh. Dubrovsky, E.V. Rozhkov
}

\title{
PROBLEMS OF DEVELOPING A DIGITAL PLATFORM FOR MUNICIPAL PROPERTY MANAGEMENT (THE CASE OF THE CITY OF PERM)
}

\footnotetext{
The article is devoted to the issues associated with the introduction of a digital property management platform at municipal level.

The methodological basis of the study includes theoretical provisions of the method of system analysis, the theory of digitalization of systems, calculation and experimental methods to simulate a digital platform for municipal property management, as well as the methods based on the theory of functional specialization and the theory of restructuring. The authors used a method of observation, which identified the goals to be achieved and the processes to be performed to digitalize an urban property platform. The analysis of the data collected was carried out to verify whether a program-goal approach was needed to perform property digitalization.
} 
The results demonstrate that a lack of digital innovation platforms in the management of municipal property has serious consequences for the development of urban economy, which may further lead to a deeper gap in innovative development in comparison with digitally developed cities. Today Morion Digital, a technopark in Perm, rated A+ among all Russian technoparks, is ready to develop any digital platforms both for the city of Perm and for other regional municipalities.

The theoretical and practical relevance of the study suggests that the digital platform for property management will grant users an online access to $100 \%$ services in proactive mode, freeing them from visits to authorised departments. Digital platforms would provide the Perm residents with a large selection of services at low/no cost, useful functions, as well as individual services.

Keywords: urban property, platform, digitalization, smart city, economic benefit.

Valery Zh. Dubrovsky - Doctor of Economics, Professor, Director of the Institute of Economics, Ural State University of Economics, Ural State University of Economics, e-mail: dubr@usue.ru.

Evgeny V. Rozhkov - PhD Student, Department of Enterprise Economics, Ural State University of Economics, e-mail: rozhkov@pochtobank.ru.

Received 08.12.2020 Accepted 28.12.2020 Published 31.03.2021 